\section{Agenesis of the corpus callosum in a newborn with Turner mosaicism}

\author{
Ester Pereira,1,2 Monica Rebollo Polo,3 \\ Jordi Muchart López, 3 \\ Thais Agut Quijano,4 \\ Alfredo García-Alix, ${ }^{4}$ Carmen Fons ${ }^{2}$ \\ 1Department of Pediatrics, Centro \\ Hospitalar de Leiria-Pombal EPE, Leiria, \\ Portugal; 2Department of Neurology, \\ 3Department of Neuroradiology, \\ 4Department of Neonatology, Hospital \\ Sant Joan De Déu, Barcelona, Spain
}

\section{Abstract}

The agenesis of the corpus callosum results from a failure in the development of the largest fiber bundle that connects cerebral hemispheres. Patient's outcome is influenced by etiology and associated central nervous system malformations. We describe a child with Turner syndrome (TS) mosaicism, with particular phenotype features and a complete agenesis of the corpus callosum. To our knowledge, this is the second case report of TS mosaicism associated with complete agenesis of the corpus callosum. Anatomical brain magnetic resonance imaging and diffusion tensor imaging were useful to confirm the complete absence of the corpus callosum, evaluate associated central nervous system malformations, visualize abnormal white matter tracts (Probst bundles) and assess the remaining commissures.

\section{Introduction}

The agenesis of the corpus callosum (ACC) results from a failure, during the early stages, in the development of the largest fiber bundle that connects cerebral hemispheres. An increasing number of cases of ACC are detected during pregnancy by fetal ultrasound. ${ }^{1} \mathrm{~A}$ recent neonatal and prenatal imaging study reported that ACC has an incidence of at least 1:4000 live-births. ${ }^{2}$ Around $30-45 \%$ of cases have an identifiable cause: $10 \%$ are related to chromosomal abnormalities and $20-35 \%$ to a recognizable genetic syndrome. ${ }^{3}$ Patient's outcome is influenced by etiology and associated central nervous system (CNS) malformations. 1,3 We describe the clinical features and genetic findings of a child with complete ACC. We also discuss the role of anatomical brain magnetic resonance imaging (MRI) and diffusion tensor imaging (DTI).

\section{Case Report}

A caucasian female was the second child of healthy unrelated parents. Family history was uneventful. Her mother was 27-year-old and had no history of previous abortions. Pregnancy was uncomplicated until the third trimester, when ACC and ventriculomegaly were detected by ultrasound. The amniotic fluid chromosome analysis was not performed. Since pregnancy was almost full-term, we decided to defer prenatal MRI after the birth of the child. The infant was delivered at 39 weeks' gestation by induced vaginal delivery. Amniotic fluid was meconial and tracheal aspiration was performed, followed by ventilation with positive pressure for about 30 seconds. Apgar scores were 5/7/9. No ventilation was required afterwards. The newborn physical examination showed birth weight of $3440 \mathrm{~g}$ (25-50 ${ }^{\text {th }}$ percentile), length of $49 \mathrm{~cm}\left(25-50^{\text {th }}\right.$ percentile) and head circumference of $35 \mathrm{~cm}$ (50-75 th percentile). She presented redundant nuchal cutaneous fold, prominent forehead, wide nasal bridge, hypertelorism, mandibular hypoplasia, high arched palate, long philtrum and thin superior lip. Upper extremities were short with redundant skin. Skeletal survey, chest X-ray, echocardiography, abdominal ultrasound and brainstem auditory evoked potentials were normal. During an ophthalmic exam, a left eye congenital glaucoma was identified. Brain MRI with DTI (14-day-old) showed total commissural agenesis and secondary colpocephaly. Tractography of the corpus callosum fibers revealed normal development of bilateral Probst bundles. No other midline, cortical or posterior fossa anomalies were detected (Figures 1 and 2). Karyotype exhibited a mosaic $46, \mathrm{X},+\operatorname{mar}(17) / 45, \mathrm{X}(3)$. One cellular line corresponded to an $\mathrm{X}$ monosomy and the other predominant one presented a marker chromosome which hybridized with the centromeric probe for the X chromosome, as determined by fluorescence in situ hybridization.

Left eye congenital glaucoma was treated by goniotomy at 5 months of age. At 15 months, she had global hypotonia and could not sit alone. Social contact was adequate. No seizures were detected. She also presented severe growth failure: at 15 month, her weight was $6475 \mathrm{~g}$ (below $5^{\text {th }}$ percentile), length $66 \mathrm{~cm}$ (below $5^{\text {th }}$ percentile) and head circumference $45 \mathrm{~cm}$ ( $25^{\text {th }}$ percentile)

\section{Discussion and Conclusions}

ACC can be associated with several consistent chromosomal rearrangements. ${ }^{4}$ In our case report, karyotype analysis surprisingly showed a TS mosaicism, since there weren't
Correspondence: Ester Preciosa Maio Nunes Pereira, Centro Hospitalar de Leiria-Pombal, EPE, Rua das Olhalvas, Pousos, 2410-197 Leiria, Portugal.

Tel. +351.244.817.000 - Fax: +351.244 .817 .083 .

E-mail: esterpmnpereira@gmail.com

Key words: central nervous system malformations, corpus callosum, Turner syndrome.

Contributions: EP, design, data acquisition, drafting the article, final approval; MRP, JML, TAO AGA, CF, design, data acquisition, critical review, final approval.

Conflict of interests: the authors declare no potential conflict of interests.

Funding: none.

Received for publication: 7 October 2013

Revision received: 15 November 2013.

Accepted for publication: 12 December 2013.

This work is licensed under a Creative Commons Attribution NonCommercial 3.0 License (CC BYNC 3.0).

(C) Copyright E. Pereira et al., 2014

Licensee PAGEPress, Italy

Pediatric Reports 2014; 6:5112

doi:10.4081/pr.2014.5112

prenatal signs of TS on ultrasound (hygroma colli, fetal hydrops, cardiac defects or increased nuchal translucency), ${ }^{5}$ and the newborn had only subtle dysmorphic features, without the characteristic edema of the dorsa of the hands and feet, low birth weight or decreased length. ${ }^{6}$

Callosal involvement in TS has been previously described in other reports of callosal dysgenesis, ${ }^{7-10}$ as well as group analysis of callosal morphology.11,12 To our knowledge, there are only four other published case reports of TS associated with ACC (Table 1).9-12 Furthermore, this is the second case report of TS mosaicism, the other being a $45, \mathrm{X} / 46, \mathrm{X}, \mathrm{r}(\mathrm{X})$ mosaicism. ${ }^{7}$

Prenatal diagnosis of ACC can be suspected when fetal ultrasound show no cavum septum pellucidum and pericallosal artery, by the 18$20^{\text {th }}$ weeks' gestation.1,4 In our patient the diagnosis was delayed until the third trimester, probably when colpocephaly became evident.

ACC is frequently associated with malformations of cortical development. ${ }^{13}$ The incidence of severe mental retardation and epilepsy depends on their co-existence. ${ }^{3}$ As MRI shows a very detailed picture of the brain, it allowed us not only to confirm the absence of the corpus callosum, which was previously suspected in fetal ultrasound, but also to assess the associated CNS malformations. In our patient, a 
diagnosis of isolated complete ACC was done, as no other CNS malformations were documented (Figure 1). We also used DTI and tractography to better visualize the 3D picture of white matter tracts. We could confirm that there were no fibers crossing the midline and demonstrate the well-defined Probst bundles consisting of misrouted callosal axons that run
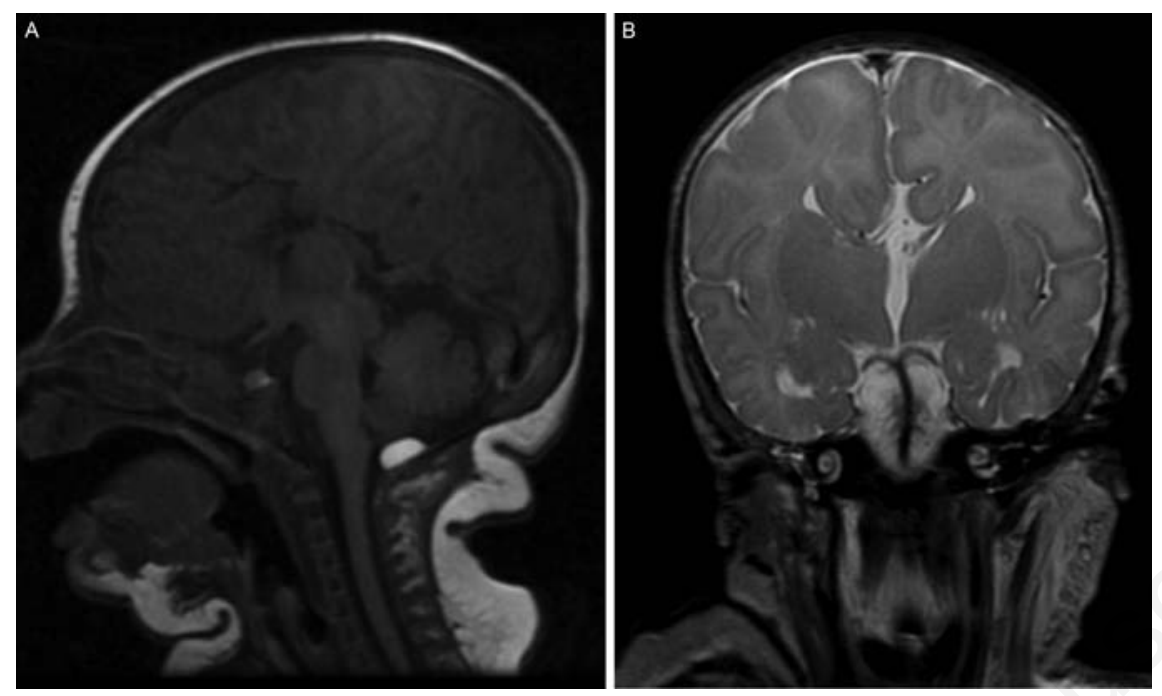

Figure 1. Brain magnetic resonance imaging. A) Midsagittal T1 FLAIR. Absence of the corpus callosum. B) Coronal T2 fast spin echo image. Typical Viking helmet or moose head configuration of the ventricles and high third ventricle extending into the interhemispheric fissure. antero-posteriorly and parallel to the interhemispheric fissure. Probst bundles are more common in patients with complete ACC without abnormalities beyond the midline or malformations of cortical development, 13 as in our case report. On the other hand, DTI and tractography also confirmed the absence of anterior and hippocampal commissures. Because

ACC is part of a spectrum of commissural anomalies, it is important to evaluate the remaining commissures, which can simultaneously be enlarged, hypoplastic or absent.13 Even though the anterior commissure is intact in most patients with primary ACC, the combined absence of multiple commissures, particularly of the anterior commissure, may represent a more severe form of cerebral malformation than ACC alone. ${ }^{2}$ It is not known if these patients will have worst interhemispheric integration. An association with a more complex picture of multiple malformations is present in $65 \%$ of the cases of ACC. ${ }^{3}$ A detailed clinical evaluation and examination of organs and systems is therefore required. The most frequent non-CNS anomalies are craniofacial and midline abnormalities (macrocephaly, hypertelorism, broad and depressed nasal bridge, high arched palate, and palate defects).1,3,14 Our patient had some of these. Other skeletal, cardiac and ocular malformations need to be excluded. It is difficult to establish a prognosis for ACC and TS. ACC is associated with a broad range of clinical manifestations, ranging from conditions within normal limits to severe psychomotor delay. ${ }^{3} \mathrm{On}$ the other hand, phenotypic predictions for a given patient with TS based on karyotype are unreliable, particularly in cases of mosaicism. However, the presence of a ring or a marker chromosome is associated with a greater risk of mental retardation and atypical phenotypic

Table 1. Clinical features of 5 patients with Turner Syndrome and agenesis of the corpus callosum.

\begin{tabular}{|c|c|c|c|c|c|}
\hline & $\begin{array}{c}\text { Araki et al. }{ }^{12} \\
1987\end{array}$ & $\begin{array}{c}\text { Kimura et al.11 } \\
1990\end{array}$ & $\begin{array}{c}\text { Abd et al.10 } \\
1997\end{array}$ & $\begin{array}{l}\text { Lee } \text { et al. }{ }^{9} \\
2008\end{array}$ & $\begin{array}{c}\text { Pereira et al. } \\
2013\end{array}$ \\
\hline Genotype & $45, X$ & $45, X$ & 45,X/46,X,r $(X)$ mosaic & $45, X$ & $46, \mathrm{X},+\mathrm{mar} / 45, \mathrm{X}$ mosaic \\
\hline Motor development delay & + & + & + & + & + \\
\hline Learning disability & Normal & Profound & Mild & Normal & NA \\
\hline $\begin{array}{l}\text { Neurological features } \\
\text { Optic nerve hypoplasia } \\
\text { Hypotonia } \\
\text { Generalized joint laxity } \\
\text { Seizure }\end{array}$ & $\begin{array}{l}- \\
- \\
-\end{array}$ & $\begin{array}{l}+ \\
+ \\
- \\
-\end{array}$ & $\begin{array}{l}- \\
- \\
+ \\
-\end{array}$ & $\begin{array}{l}- \\
- \\
- \\
+\end{array}$ & $\begin{array}{l}- \\
+ \\
- \\
-\end{array}$ \\
\hline $\begin{array}{l}\text { Facial features } \\
\text { Hypertelorism } \\
\text { Low-set ears } \\
\text { Highly arched palate } \\
\text { Wide mouth }\end{array}$ & $\begin{array}{l}- \\
- \\
- \\
-\end{array}$ & $\begin{array}{l}+ \\
+ \\
+ \\
-\end{array}$ & $\begin{array}{l}+ \\
- \\
- \\
+\end{array}$ & $\begin{array}{l}+ \\
- \\
- \\
-\end{array}$ & $\begin{array}{l}+ \\
- \\
+ \\
-\end{array}$ \\
\hline $\begin{array}{l}\text { Other dysmorphic features } \\
\text { Short fingers } \\
\text { Single palmar crease } \\
\text { Cubitus valgus } \\
\text { Upper arm short relative to trunk } \\
\text { Low hairline } \\
\text { Webbed neck } \\
\text { Multiple pigmented nevi }\end{array}$ & $\begin{array}{l}- \\
- \\
- \\
- \\
+ \\
- \\
+\end{array}$ & $\begin{array}{l}+ \\
- \\
+ \\
- \\
- \\
- \\
+\end{array}$ & $\begin{array}{l}- \\
+ \\
+ \\
+ \\
- \\
- \\
-\end{array}$ & $\begin{array}{l}- \\
- \\
+ \\
- \\
+ \\
+ \\
+\end{array}$ & $\begin{array}{l}- \\
- \\
- \\
+ \\
- \\
- \\
-\end{array}$ \\
\hline Renal anomaly & + & + & - & - & - \\
\hline Coarctation of aorta & - & - & - & + & - \\
\hline Short height & + & + & - & + & - \\
\hline
\end{tabular}




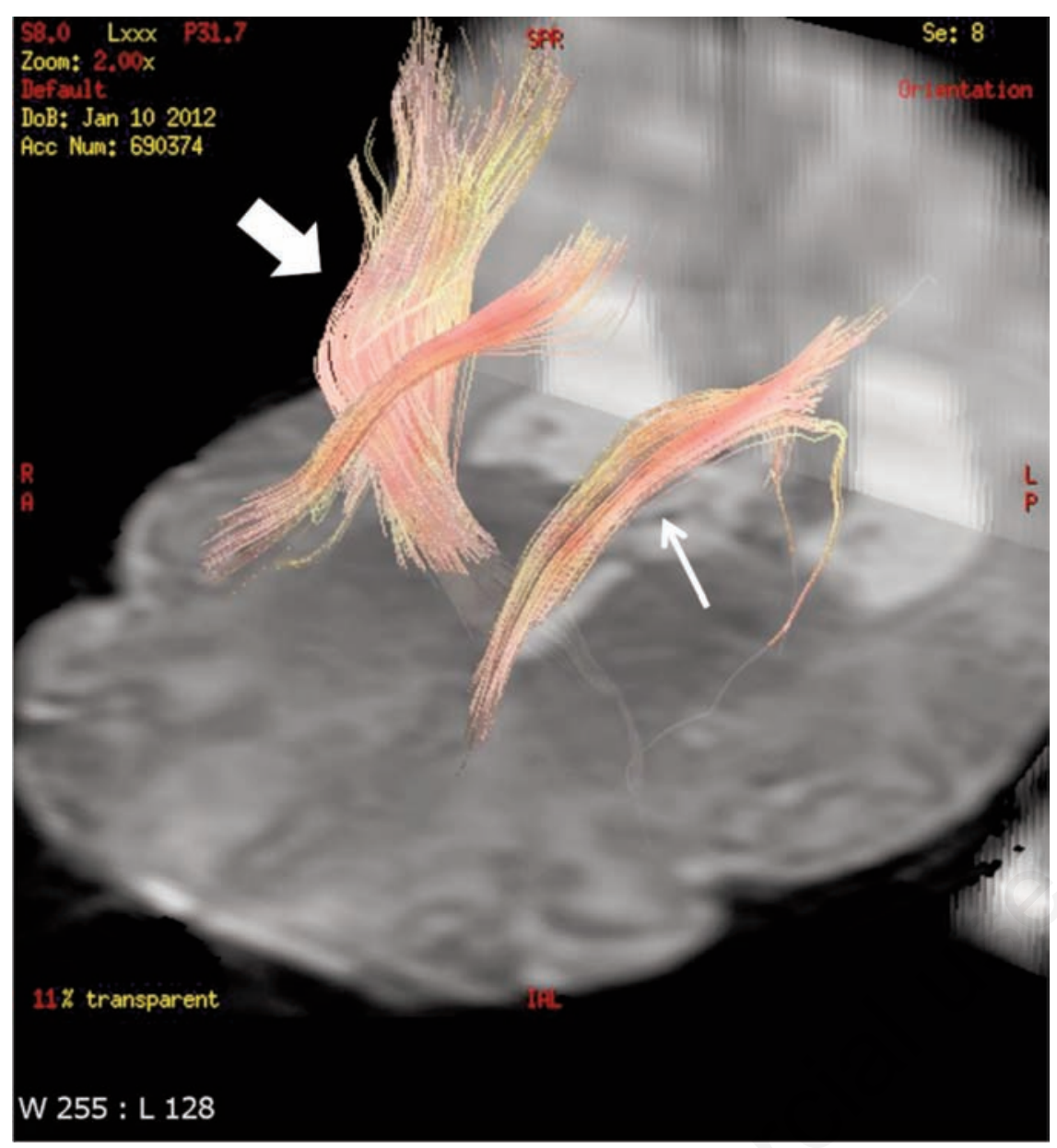

Figure 2. Tractography. Probst bundle parallel to the lateral ventricle (thin arrow). Corticospinal tract (thick arrow).

features. ${ }^{15}$ Follow-up is required, since medical comorbidities related to TS, as well as any developmental delay, learning disabilities and behavior problems attributable to both TS and ACC may become apparent.

In conclusion, we describe a case report of a child with TS mosaicism, with particular phenotypic features, associated with complete ACC detected prenatally. Brain MRI and DTI were useful to confirm the absence of the corpus callosum, evaluate associated CNS malformations, visualize abnormal white matter tracts (Probst bundles) and assess the remaining commissures.
Pediatr Neurol 2006;34:186-93.

4. Dobyns WB. Absence makes the search grow longer. Am J Hum Genet 1996;58:716.

5. Papp C, Beke A, Mezei G, et al. Prenatal diagnosis of Turner syndrome: report on 69 cases. J Ultrasound Med 2006;25:711-7.

6. Rapaport R. Disorders of the gonads. In: Kliegman RM, Behrman RE, Jenson HB, Stanton BF (eds). Nelson Textbook of Pediatrics. 18thed. Philadelphia: Saunders Elsevier; 2007. pp 2386-2389.

7. Lee YY, Hung J, Chang TY, Huang CC. Agenesis of the corpus callosum in Turner's syndrome: report of a case and review of the literature. Acta Neurol Taiwan 2008;17:194-8.

8. Abd SE, Wilson L, Howlin P, et al. Agenesis of the corpus callosum in Turner syndrome with ring $X$. Dev Med Child Neurol 1997;39:119-24.

9. Kimura M, Nakajima M, Yoshino K. Ullrich-Turner syndrome with agenesis of the corpus callosum. Am J Med Genet 1990;37:227-8.

10. Araki K, Matsumoto K, Shiraishi T, et al. Turner's syndrome with agenesis of the corpus callosum, Hashimoto's thyroiditis and horseshoe kidney. Acta Paediatr Jpn 1987;29:622-6.

11. Fryer SL, Kwon H, Eliez S, Reiss AL. Corpus callosum and posterior fossa development in monozygotic females: a morphometric MRI study of Turner syndrome. Dev Med Child Neurol 2003;45:320-4.

12. Cutter WJ, Daly EM, Robertson DM, et al. Influence of $\mathrm{X}$ chromosome and hormones on human brain development: a magnetic resonance imaging and proton magnetic resonance spectroscopy study of Turner syndrome. Biol Psychiatry 2006;59:273-83.

13. Hetts SW, Sherr EH, Chao S, et al. Anomalies of the corpus callosum: an MR analysis of the phenotypic spectrum of associated malformations. AJR Am J Roentgenol 2006;187:1343-8.

14. Serur D. Agenesis of the corpus callosum: clinical, neuroradiological and cytogenetic studies. Neuropediatrics 1988;19:87-91.

15. Sybert VP, McCauley E. Turner's Syndrome. N Engl J Med 2004;351:1227-38. 